\title{
SPIROMETRIC AND BRONCHOSPIROMETRIC STUDIES IN FIVE-RIB THORACOPLASTIES
}

\author{
BY \\ TORSTEN LINDAHL \\ From Söderby Hospital, Uttran, Sweden, and the Department of Surgery, Sabbatsberg Hospital, Stockholm
}

(RECEIVED FOR PUBLICATION JULY 6, 1954)

It is a well-known fact that thoracoplasty places a severe strain on the patient, affecting in particular the interchange of gases. Stead and Soucheray (1952), of Minneapolis, studied these problems during the first 16 to 20 hours after thoracoplasty operations. It must suffice here to mention some of the principal data in their investigation. They found a substantia! increase in the respiratory minute volume, and no less than $58 \%$ of that increase was referable to the ventilation of a functionally dead space. The tidal air decreased (a traumatic effect), but it was compensated by an increased frequency of respiration to enable the carbon dioxide to be expired. It is then that the patient needs the respiratory reserve of 70 to $85 \%$ which is generally considered to be essential for the operation. If the blood shows a high carbon dioxide content the day after the operation then there is ventilatory insufficiency, and tracheotomy may be a life-saving measure.

The operation is followed by a period of recovery during which the pulmonary function steadily improves. Opinions vary as to the duration of this period. Jacobaeus, Frenckner, and Björkman (1932) spoke of three years ; Birath (1944) demonstrated functional improvement from two to seven months after the operation. More recent investigations at frequent intervals postoperatively by Gaensler (1952) confirm that recovery is substantially complete within two months. It seems advisable, therefore, to keep the patient in hospital for about six to ten weeks after operation for physiotherapy.

Notwithstanding every possible measure there still remains a varying degree of functional loss after thoracoplasty. To what, then, is this to be attributed? Attention should be drawn, first and foremost, to investigations by Björkman (1934) and Björkman and Carlens (1951) and by Pinner and others (1942), whodemonstrated bilateral'y reduced function in spite of unilateral surgery. Those factors, besides collapse of the pulmonary parenchyma that are accounted a deleterious effect relative to the functional end-result, consist chiefly of pleural complications with reduced diaphragmatic motion, as well as destruction of the thoracic wall and varying degrees of scoliosis. Gaensler and Strieder $(1950,1951)$ described how the function is reduced by destruction of the thoracic wall. Movements of the ribs are restricted, for instance, by disturbed innervation, and this is of major importance even if the six or seven lower ribs are left intact. The diaphragmatic motion on the operated side is said to be invariably reduced (Rayl and Gaensler, unpublishèd data reported by Gaensler and Strieder, 1950). It is less effective because the relaxation of the diaphragm during expiration is not supported by the normal simultaneous contraction of the thoracic wall (Herxheimer, 1949). The degree of destruction of the thoracic wall is naturally dependent on the number of ribs removed. Watson and Gaensler (1952) showed that the functional impairment is proportional to the extent of the thoracoplasty. The relationship to the extent of the parenchymal process, on the other hand, cannot be judged from these thoracoplasty series.

The pathophysiological significance of scoliosis has long been known. Unfortunately, some degree of this deformity virtually always follows thoracoplasty, where it takes the form of rotoscoliosis. It is believed to be caused by such factors as asymmetrical freeing of a number of muscle attachments, notably those of the scalenus, pectoralis minor, and erectores dorsi muscles, as well as excision of the first rib and the anterior segments of others, together with the transverse processes of the vertebrae. The factor of greatest significance, however, is probably the number of ribs resected. Cournand and others (1941) reported that the maximum breathing capacity fell by $15 \%$ in a thoracoplasty series, but showed that this functional loss was considerably greater in the event of more pronounced scoliosis. Powers and Himmelstein (1951), in two cases complicated by scoliosis examined before and after the operation, found 
the maximum breathing capacity to be reduced by more than $30 \%$. They had investigated 24 cases of three- to 11-rib thoracoplasties.

A major contributory cause of functional losses consists, of course, in the pleural complications (Bruce, 1946). Watson and Gaensler studied threerib thoracoplasties and found a reduction of the maximum breathing capacity by $28 \%$ in cases with, and by $12 \%$ in cases without, pleural complications. In general, however, such complications do not affect a thoracoplasty series to the same degree as they do some other forms of active therapy, such as artificial pneumothorax and resection.

What, then, is the effect of thoracoplasty on the various components of pulmonary ventilation ? A number of investigations, including those of Cournand and others, Birath, Gaensler and others, and Powers and Himmelstein, have shown that the vital capacity falls to a varying degree, the figures ranging from 20 to $30 \%$. Gaensler and Cugell (1952), on determining the lung volume by double-lumen catheter, showed that no decrease occurred in the residual volume, but that the functional loss largely affected the inspiratory capacity. This reduction of function was also found to involve the contralateral lung. An increase of the relative residual volume can therefore be expected, and hence an existing emphysema (contrary to a widely held belief) cannot be improved by collapse therapy. The maximum breathing capacity, as mentioned above, falls. The figures here generally range from 12 to $18 \%$.

Bronchospirometric examinations have shown that the oxygen uptake, like the vital capacity and the minute volume, falls on the operated side. Incidentally, the values for these show about the same decrease, provided there are no pleural complications, which chiefly affect the oxygen uptake. Gaensler, Watson, and Patton (1953) investigated 22 right six-rib thoracoplasties. The oxygen uptake fell by about $12 \%$, and the final figure for the thoracoplasty side was $23 \%$. The corresponding figure for the vital capacity was about $25 \%$.

It is evident from the foregoing that a large number of factors must be taken into account when appraising the functional losses in thoracoplasty, the foremost being the conditions in the pleura, the operative method, the number of ribs resected, the scoliosis, and in some degree the extent of the pathological process. The value of investigations in the literature is appreciably limited by these circumstances. Moreover, comparative investigations are often carried out at different laboratories and by different personnel. For these reasons it was felt advisable to select from the Söderby Hospital series as homogeneous a group of minor thoracoplasties as possible for the study of the functional results. Further, I found some impor흘. tance attached to elucidation of the functionaf results obtained with our operative method, thus enabling a comparison to be made with othe forms of thoracoplasty that are now being devel $\overrightarrow{0}$ oped, especially in connexion with resection.

\section{MATERIAL}

In selecting the cases for this series the aim was to take only those with the least possible pleurato reactions or none at all. A fully healthy contra lateral lung was a further desideratum. It was nof possible, however, to satisfy these requirements to the full.

The investigation comprised 23 patients who had undergone five-rib thoracoplasties, 11 on the right and 12 on the left side. Nine were women and 14 were men, and the ages at operation ranged from 23 to 62 years, the mean age being 36 .

The operations were performed during the $\overrightarrow{0}$ period from 1950 to 1952, all except one by Semb's method involving extensive apicolysis. In the single exception the first rib was left intact. A two-stage procedure was employed in six cases the others being single-stage operations. Alb patients received extrafascial pneumothoraxo therapy. Appreciable complications occurred in two cases. One patient had paralysis of the dia- $\frac{3}{3}$ phragm, but to all appearances had fully recovered? within a few months. In the other a traumatic haemopneumothorax occurred at operation, but here, too, the condition resolved almost completely

The period of observation ranged from one to three and a half years.

The duration of the disease, at operation, varied from one to 16 years, the average being six years Pleurisy had occurred on the thoracoplasty side in nine cases, including two doubtful ones, but ino no case on the contralateral side. Therapeutic pneumothorax had been induced bilaterally ino three cases and on the thoracoplasty side in two cases. Artificial pneumothorax had been attemp- $N$ ted in 10 cases, including one with adhesion section.

Twenty-one patients resumed work within one year after the operation, the other two after one year and five months. No progression ensued.

At the time of follow-up examination one patientes showed diabetes as well as residual cavitation and ${ }_{0}^{+}$ positive sputum cultures. Suspected residual cavities and positive cultures were found in a furthero case. In all cases direct sputum smears were nega $-\frac{?}{D}$ tive. One patient had asthma with dust allergy응 The blood sedimentation rate ranged from 2 to $26 \mathrm{~mm}$. and averaged $9 \mathrm{~mm}$. 
Fully healthy contralateral lungs were found in 11 cases. Minimal inactive lesions in the apical field were observed in five cases; a few lesions from the apex to the lateral part of the first or second intercostal spaces in seven. Two cases were regarded as stationary and the others as healed or healing.

In evaluating the function some importance was attached to the scoliosis. In this investigation I sought to measure this deformity by marking the spinal processes on the back and measuring the curvature formed thereby in relation to a straight line from the nape to the upper lumbar vertebrae. This measurement was done in 21 cases, and the degree of scoliosis ranged up to $2.5 \mathrm{~cm}$., with a mean of exactly $1 \mathrm{~cm}$. These results were then compared with corresponding measurements on radiographs (Fig. 1) taken with the beam parallel to the mediastinum at the level of the manubrium, where the scoliosis reaches its maximum. This technique served to eliminate rotation of the spinal column, besides enabling the deviation of the trachea to be measured. The scoliosis was thus measured in 18 cases, the figures ranging up from 0 to $20 \mathrm{~mm}$. and averaging precisely $1 \mathrm{~cm}$. (Table I).

The deviation of the trachea was determined in 18 cases. The greatest deviation towards the operated side amounted to $18 \mathrm{~mm}$., and the mean was 9.4 (Table I and Fig. 1).
TABLE I

SCOLIOSIS AND TRACHEAL DEVIATION

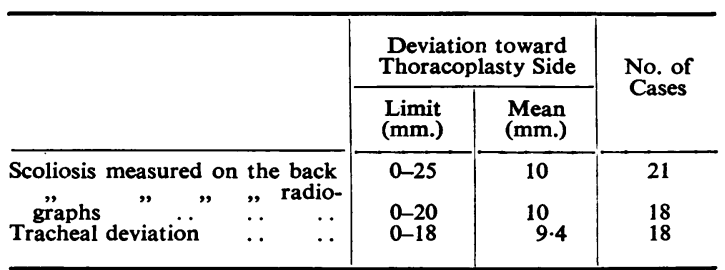

Several patients had had pleurisy or had undergone artificial pneumothorax. One operation was further complicated by haemothorax. This notwithstanding, the persisting pleural reactions were very slight, incidentally a major consideration when the series was selected. Six cases showed no radiological signs of pleural reactions. In 15 cases there was some rounding of the sinus on the thoracoplasty side, and in five cases similar changes on the contralateral side (Table II).

Experience shows that such an inappreciable residue of pleural affections as was found here does not influence the function to any major degree. That this was true in the present series is evident from the equal reduction of the oxygen uptake, the respiratory minute volume, and the vital capacity. Pleural fibrosis with fixation of the diaphragm is associated with a lower oxygen uptake in relation to minute volume and vital capacity (Bruce, 1946). The diaphragmatic move-

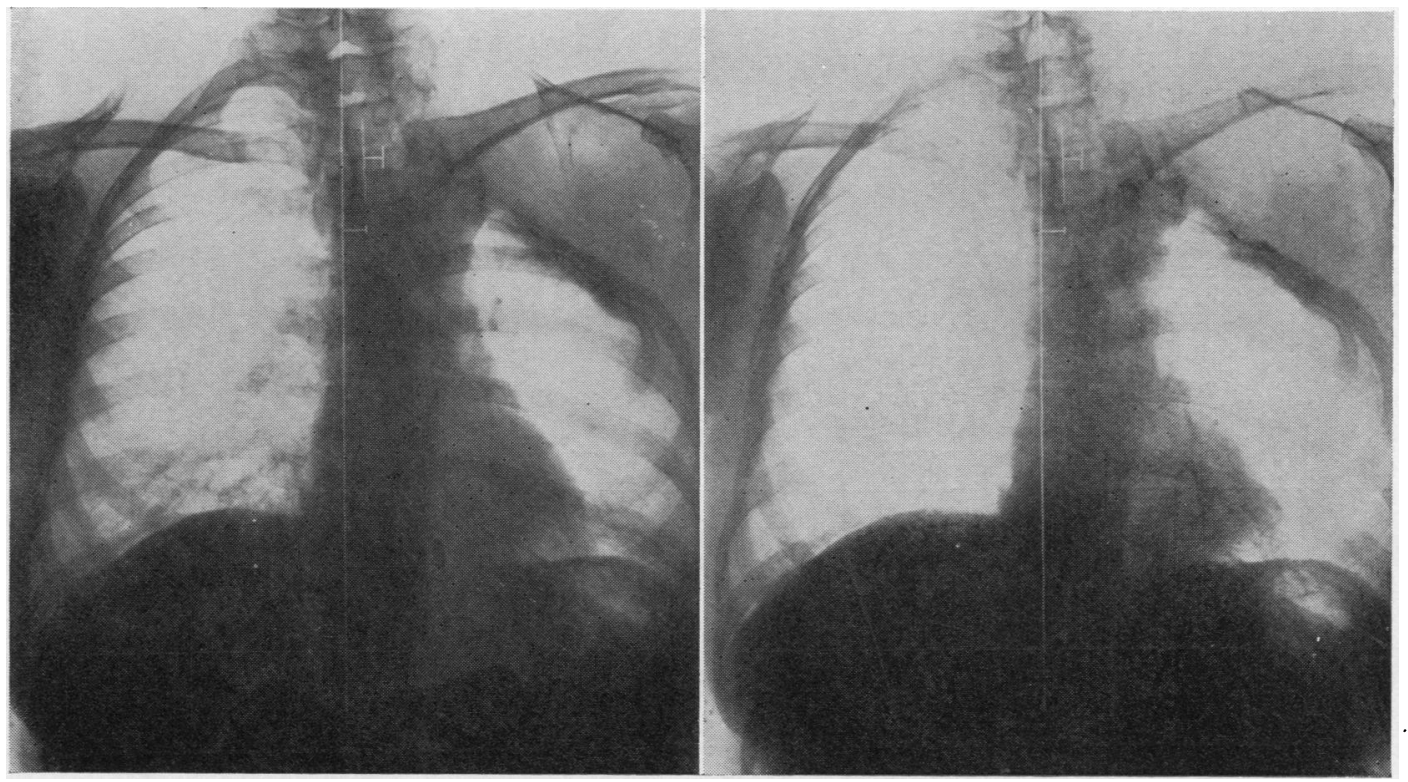

FIG. 1.-The radiographic method of measuring deviation of the trachea and the degree of scoliosis in five-rib thoracoplasty. 
TABLE II

PLEURAL LESIONS

\begin{tabular}{|c|c|c|}
\hline & $\begin{array}{c}\text { Side of } \\
\text { Operation }\end{array}$ & $\begin{array}{c}\text { Contralateral } \\
\text { Side }\end{array}$ \\
\hline $\begin{array}{l}\text { None } \\
\text { Slight rounding of sinus diaphragm } \\
\text { Moderate rounding of sinus dia- } \\
\text { phragm } \ldots \\
\text {. . }\end{array}$ & $\begin{array}{r}8 \\
11 \\
4\end{array}$ & $\begin{array}{r}18 \\
4 \\
1\end{array}$ \\
\hline
\end{tabular}

ments were measured by Källqvist's method in seven patients, and were surprisingly good.

\section{METHODS}

In this series the pulmonary function was studied spirometrically by the method reported by Birath (1944). The patient breathes in a closed system containing a mixture of oxygen and hydrogen. The maximum breathing capacity is recorded in the same apparatus, the patient breathing at a frequency of 40 to 70 respirations per minute for 15 seconds.

The bronchospirometric function was determined by means of Björkman's apparatus as described in 1934. Carlens' (1949) double-lumen catheter was used in the examinations.

All determinations of the pulmonary function, both before and after operation, were performed at the same laboratory by the same examiner. Considerable importance must be attached to this factor in tests of the type in question. The patient has to be prompted to optimal performances, and the results attained must be correctly evaluated and the tests repeated if the patient has not cooperated satisfactorily. The values were calculated according to the formula of Baldwin, Cournand, and Richards (1948).

\section{RESUlts}

The values for maximum breathing capacity and vital capacity immediately before operation averaged 97 and 3.81 . respectively, compared with the calculated 108 and 3.71 . The corresponding values after operation were 92 and 3.2 1., or a decrease of $5 \%$ in maximum breathing capacity and $16 \%$ in vital capacity. This functional loss is comparatively small and can chiefly be compared with the

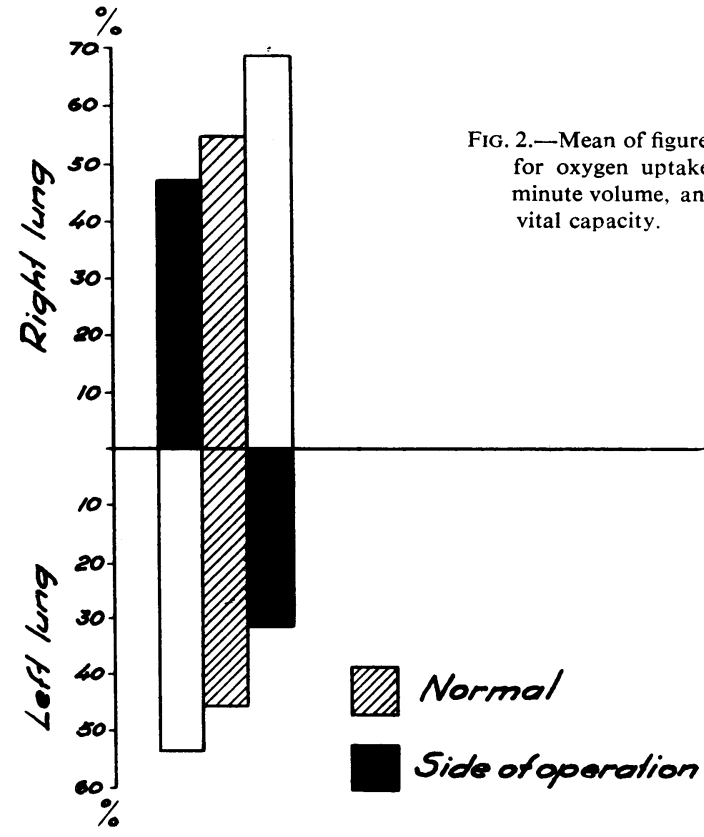

values found by Gaensler and others in cases with extrapleural pneumothorax, an operation which, so far as collapse is concerned, usually corresponds to a five- or six-rib thoracoplasty. Functionally, therefore, the two methods of treatment are comparable. It should be borne in mind, however, that the indications for these two operations are different, since extrapleural pneumothorax has the character of temporary collapse. The functional results which Gaensler and others found in extrapleural pneumothorax, and which are shown in Table $\mathrm{V}$ and Fig. 3, refer to the conditions six months after operation and not to the final state after termination of refills.

TABLE III

RESULTS OF SPIROMETRY BEFORE AND AFTER FIVE-RIB THORACOPLASTY*

\begin{tabular}{|c|c|c|c|c|c|c|c|c|c|c|c|}
\hline \multirow{3}{*}{ Spirometry } & & \multirow{3}{*}{$\underset{\text { (1./min.) }}{\text { M.B.C. }}$} & \multirow{3}{*}{ (i.) } & \multirow{3}{*}{ R.V. } & \multirow{3}{*}{$\frac{\text { R.V. }}{\text { T.C. }} \times 100$} & \multicolumn{2}{|c|}{ M.B.C. } & \multicolumn{2}{|c|}{ v.C. } & \multicolumn{2}{|c|}{$\frac{\text { R.V. }}{\text { T.C. }} \times 100 \%$} \\
\hline & & & & & & Right & Left & Right & Left & Right & Left \\
\hline & & & & & & \multicolumn{2}{|c|}{ Thoracoplasty } & \multicolumn{2}{|c|}{ Thoracoplasty } & \multicolumn{2}{|c|}{ Thoracoplasty } \\
\hline $\begin{array}{l}\text { Calculated values } \\
\text { Before operation } \\
\text { After " } \quad . .\end{array}$ & $\begin{array}{l}\cdots \\
\cdots \\
\cdots\end{array}$ & $\begin{array}{r}108 \\
97 \\
92\end{array}$ & $\begin{array}{l}3 \cdot 7 \\
3 \cdot 8 \\
3 \cdot 2\end{array}$ & $\begin{array}{l}1 \cdot 2 \\
1 \cdot 2 \\
1 \cdot 2\end{array}$ & $\begin{array}{l}24 \\
27\end{array}$ & $\begin{array}{l}90 \\
88\end{array}$ & $\begin{array}{r}103 \\
95\end{array}$ & $\begin{array}{l}3 \cdot 8 \\
3 \cdot 3\end{array}$ & $\begin{array}{l}3 \cdot 8 \\
3 \cdot 1\end{array}$ & $\begin{array}{l}24 \\
27\end{array}$ & $\begin{array}{l}24 \\
27\end{array}$ \\
\hline
\end{tabular}

* The first four columns are referable to the total series, the others to the series broken down into right and left thoracoplasties. M.B.C. = maximum breathing capacity; V.C. = vital capacity; R.V. = residual volume; T.C. = total capacity. 


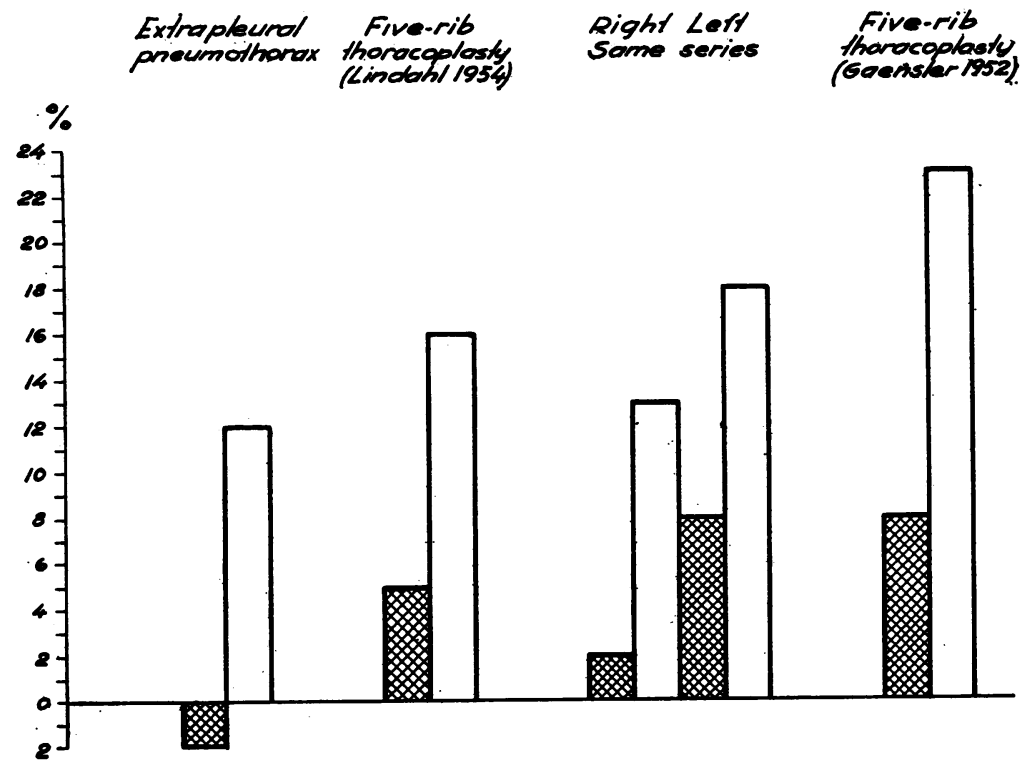

FIG. 3.-Functional loss in the present 23 cases of five-rib thoracoplasty compared with Gaensler's extrapleural $M B C$ pneumothorax series six months after operation and his five cases of five-rib thoracoplasty. (M.B.C. = maximum breathing capacity.)

\section{Vital capacity}

was postulated (Björkman, 1934 ; Björk, 1953). The oxygen uptake, respiratory minute volume, and vital capacity amounted, respectively, to 46,51 , and $45 \%$ for the right, and 30,31 , and $32 \%$ for the left, thoracoplasty cases. The mean values of these three functions, 47 and $31 \%$ respectively, thus diverged from the normal values by $8 \%$ for the right thoracoplasty and by $14 \%$ for the left thoracoplasty cases, as will be seen from Fig. 2 .

This uneven distribution of the functional loss led to investigation of the total pulmonary function in this respect. The results showed, as emerges from Tables III and V, a similar state of affairs, i.e., a greater functional loss in the left than in the right thoracoplasty cases.

The residual volume was, as expected, unchanged in the present series, the mean value being 1.2 . The relative residual volume $(\mathrm{RV} / \mathrm{TC} \times 100)$ showed only a very slight increase (Table III).

Bronchospirometry was performed before the operation in two cases only; hence no comparisons of pre- and post-operative figures are possible. However, it can be assumed with some probability that the function of the two lungs before operation was distributed more or less normally, due to the principles on which the series was selected. On studying the bronchospirometric results we immediately observe that the function was poorer in the left than in the right thoracoplasty cases under otherwise similar conditions (Table IV). A normal distribution of function of $55 \%$ for the right and $45 \%$ for the left lung

TABLE IV

RESULTS OF BRONCHOSPIROMETRY IN RIGHT AND LEFT FIVE-RIB THORACOPLASTIES COMPARED WITH 22 INVESTIGATED BY WATSON AND GAENSLER

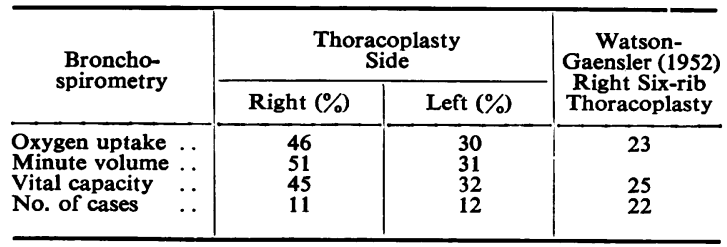

All differences with the exception of those for the maximum breathing capacity were statistically significant. Some doubt exists with regard to the values for the minute volume, though it can be eliminated by excluding one case, a right thoraco-

TABLE V

FUNCTIONAL LOSS IN PRESENT SERIES

\begin{tabular}{|c|c|c|c|c|c|c|c|}
\hline \multirow{3}{*}{$\begin{array}{l}\text { Functional } \\
\text { Loss }(\%)\end{array}$} & \multirow{3}{*}{$\begin{array}{l}\dot{\varphi} \\
\dot{\Sigma}\end{array}$} & \multirow{3}{*}{$\dot{j}$} & \multicolumn{2}{|c|}{ M.B.C. } & \multicolumn{2}{|c|}{ V.C. } & \multirow{3}{*}{ 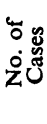 } \\
\hline & & & Right & Left & Right & Left & \\
\hline & & & \multicolumn{2}{|c|}{ Thoracoplasty } & \multicolumn{2}{|c|}{ Thoracoplasty } & \\
\hline $\begin{array}{c}\text { G a ensler a nd } \\
\text { Strieder (1950) } \\
\text { extrapleural } \\
\text { pneumothorax } \\
\text { Present series five- } \\
\text { rib thoracoplasty } \\
\text { Gaensler (1952) } \\
\text { five-rib thoraco- } \\
\text { plasty .. . }\end{array}$ & $\begin{array}{r}-2 \\
5\end{array}$ & $\begin{array}{l}12 \\
16 \\
23\end{array}$ & 2 & 8 & 13 & 18 & $\begin{array}{l}20 \\
23\end{array}$ \\
\hline
\end{tabular}

plasty (minute volume $65 \%$ for the operated lung), in which there was reason to suspect that the position of the catheter had not been satisfactory. It may be added that the figures should be interpreted with some circumspection in view of the small series. The investigation provides no explanation of why right and left thoracoplasties affect the pulmonary function differently. It seems probable, however, that the right lung may have a greater functional reserve than the left. 


\section{Discussion}

It is fully clear-and has indeed been shown by spirometric analysis - that extensive thoracoplasties are associated, besides other inconveniences, with a substantial reduction of the pulmonary function. The term "extensive" here implies total and subtotal thoracoplasties. There are comparative investigations of cases in which pneumonectomy has been combined, in one group, with thoracoplasty, in another with plombage, and in a third group no measure has been taken to prevent shifting of the mediastinum towards the pneumonectomy side. The spirometric functional loss, on stabilization of the conditions, has proved to have been greatest in the thoracoplasty group. The present investigation is not designed to clarify the prognosis with respect to healing and pulmonary circulation. Most surgeons concerned with collapse therapy have doubtless observed how extensive thoracoplasties in patients with reduced pulmonary function have been followed by respiratory insufficiency. Minor thoracoplasties, on the other hand, are generally tolerated quite well and usually lead to only a negligible or moderate functional loss. However, the small and heterogeneous series that have been reported show varying results, and in some instances poorer figures than might reasonably be expected with these operations. I was therefore prompted to select as homogeneous a series as possible with respect to pulmonary lesions, indications, and type of operation, and to investigate the spirometric function therein. This investigation confirmed that the functional loss in five-rib thoracoplasties is comparatively small and tends to be somewhat higher in left that in right thoracoplasty cases. It is known, moreover, that on correct indications the minor thoracoplasties heal well. Accordingly there is ample justification for retaining this method of treatment along with the other therapeutic measures in pulmonary tuberculosis.

\section{SUMMARY}

Earlier spirometric investigations at the time of, and at varying intervals after, thoracoplasty operations are briefly surveyed, and the causes of the observed reduction of the pulmonary function discussed. Since most of these investigations had been concerned with heterogeneous series, I selected for comparison a series comprising 23 cases of five-rib thoracoplasty. These cases were homogeneous with regard to pulmonary lesions, pleural reactions, indications, and type of operation. The pulmonary lesions were small and pleural reactions minimal or quite absent. Both the scoliosis and the deviation of the trachea were measured.

At spirometric examination one to three and a half years after operation, a reduction of 5 and $16 \%$, respectively, in the maximum breathing capacity and the vital capacity was found.

Bronchospirometry was performed before operation in two cases only. The principles applied in selection of patients justified the assumption of a more or less normal distribution of the total pulmonary function, i.e., $55 \%$ for the right and $45 \%$ for the left lung. The bronchospirometric investigation showed that the oxygen uptake, respiratory minute volume, and vital capacity had fallen by an average of $8 \%$, or from 55 to $47 \%$, in the right thoracoplasty cases, and by $14 \%$ in the left thoracoplasty cases.

The difference in functional loss between the right and left thoracoplasty cases was found to apply also to the total function of both lungs.

The results are compared with corresponding investigations by Gaensler and others in one group of similar thoracoplasty cases and one group of patients who had undergone extrapleural pneumothorax.

Since the investigation has verified a comparatively small functional loss, and since experience shows the healing results to be good in minor thoracoplasties on correct indications, it is concluded that these operations constitute a valuable method of treatment along with other therapeutic measures in pulmonary tuberculosis.

\section{REFERENCES}

Baldwin, E. de F., Cournand, A., and Richards, D. W., Jr. (1948). Medicine, 27, 243.

Birath, G. (1944). Acta med. scand., Suppl. 154.

Björk, V. O. (1953). J. thorac. Surg., 26, 67.

Björkman, S. (1934). Acta med. scand., Suppl. 56.

- and Carlens, E. (1951). Ibid., 259, 63.

Bruce, T. (1946). Acta tuberc. scand., 20, 68.

Carlens, E. (1949). J. thorac. Surg., 18, 742.

Cournand, A., and Richards, D. W., Jr. (1941). Amer. Rev. Tuberc., 44, 26.

- and Maier, H. C. (1941). Ibid., 44, 272

Gaensler, E. A. (1952). J. Lab. clin. Med., 39, 917

- and Cugell, D. W. (1952). Ibid., 40, 410, 558.

- and Strieder, J. W. (1950). J. thorac. Surg., $20,774$. (1951). Ibid., 22, 1 .

Watson, T. R., Jr., and Patton, W. E. (1953). J. Lab. clin. Med., 41, 436.

Herxheimer, H. (1949). Thorax, 4, 65.

Jacobaeus, H. C., Frenckner, P., and Björkman, S. (1932). Acta med. scand., $79,174$.

Pinner, M., Leiner, G., and Zavod, W. A. (1942). J. thorac. Surg., 11, 241.

Powers, S. R., Jr., and Himmelstein, A. (1951). Ibid., 22, 45.

Rayl, D. F., and Gaensler, E. A. Unpublished data. Reported by Gaensler and Strieder (1950).

Stead, W. W., and Soucheray, P. H. (1952). J. thorac. Surg., 23, 453. Watson, T. R., Jr., and Gaensler, E. A. (1952). Trans. nat. Tuberc. Ass., N.Y., 48, 288. 